\title{
Vitamin D status in pregnancy: Data from the Seychelles Child Development Nutrition Study
}

\author{
E. Laird ${ }^{1}$, M. Ward ${ }^{1}$, H. McNulty ${ }^{1}$, J. M. W. Wallace ${ }^{1}$, E. M. McSorley ${ }^{1}$, M. S. Mulhern ${ }^{1}$, \\ A. M. McAfee ${ }^{1}$, G. J. Myers ${ }^{2}$, P. W. Davidson ${ }^{2}$, S. W. Thurston ${ }^{2}$, C. F. Shamlaye ${ }^{3}$, G. E. Watson ${ }^{2}$, \\ E. van Wijngaarden ${ }^{2}$ and J. J. Strain ${ }^{1}$ \\ ${ }^{1}$ Northern Ireland Centre for Food and Health (NICHE) University of Ulster, Coleraine BT52 ISA, \\ ${ }^{2}$ University of Rochester, School of Medicine and Dentistry, United States, ${ }^{3}$ Ministry of Health, Seychelles
}

Maternal vitamin D status may play a significant role in early life, owing to the potential of vitamin D to modulate fetal programming and influence future bone health ${ }^{(1,2)}$. Within the UK and Ireland $\left(51-55^{\circ} \mathrm{N}\right)$, vitamin D synthesis (related to UVB exposure) is limited to approximately 6 months of the year. This has a significant negative impact on circulating concentrations of 25-hydroxyvitamin D $(25(\mathrm{OH}) \mathrm{D})$, the biological measure of vitamin D status. In Ireland, over $90 \%$ of women have been reported to be vitamin D insufficient $(<50 \mathrm{nmol} / \mathrm{l})$ during the first trimester of pregnancy, with over $70 \%$ insufficient in the subsequent trimesters ${ }^{(3,4)}$. Previous studies of $25(\mathrm{OH}) \mathrm{D}$ status in pregnancy have focused on far Northern $\left(>45^{\circ} \mathrm{N}\right)$ or Southern $\left(32^{\circ} \mathrm{S}\right)$ latitudes which both suffer from seasonality effects. No studies to date have reported $25(\mathrm{OH}) \mathrm{D}$ status during pregnancy at equatorial regions which have a constant UVB exposure. Therefore, the objective of this study was to assess $25(\mathrm{OH}) \mathrm{D}$ status in a sample of pregnant women $(n 119)$ (located at $\left.5^{\circ} \mathrm{S}\right)$ from the Seychelles Child Development Nutrition Study (SCDNS). Pregnant mothers were recruited at 13-17 weeks of gestation between 2001-2002. Blood samples were collected at this time as well as at 28 weeks and at gestation, from which serum 25(OH)D concentrations were assessed by HPLC mass spectrometry (LC-MS/MS, API 4000, AB SCIEX, USA). Mean vitamin D status across all time-points was considered optimal and above the lower cut-off for sufficiency $(25(\mathrm{OH}) \mathrm{D}>50 \mathrm{nmol} / \mathrm{l})($ Fig 1$)$.

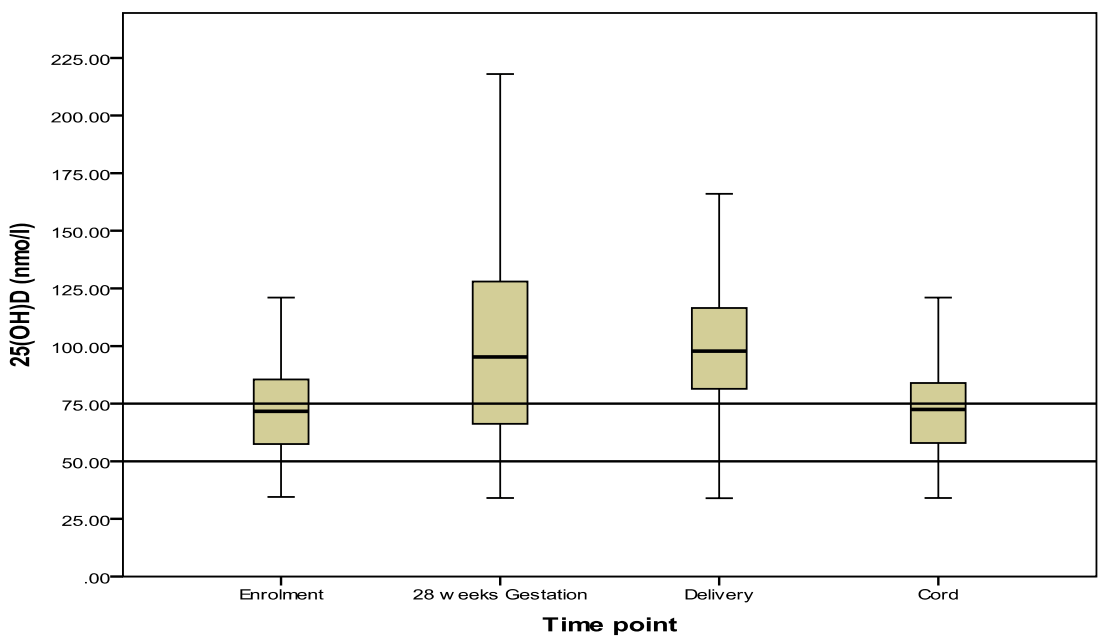

$75 \mathrm{nmol} / \mathrm{l}$; higher optimal cut-off

50nmol/1; lower optimal cut-off

Figure 1: Median 25(OH)D concentration during pregnancy with inter-quartile range.

Concentrations of $25(\mathrm{OH}) \mathrm{D}$ were found to increase significantly from enrolment to 28 weeks $(P=0.04)$ and from enrolment to delivery $\left(P<0.01\right.$; Repeated measures ANOVA) (data not shown). In contrast to the poor status observed in Northern latitude populations ${ }^{(3,4)}$, the findings of this study demonstrate that a vitamin D concentration of between 75 and $100 \mathrm{nmol} / \mathrm{l}$ can be achieved during pregnancy. These findings highlight the need for greater awareness of vitamin D inadequacy in pregnancy and support the call for interventions to improve vitamin D status in this population group in geographical areas with limited UVB exposure.

This work was supported by grants from the US National Institute of Environmental Health Sciences, National Institutes of Health, the Government of Seychelles and by the EU through its Sixth Framework Programme.

1. McGrath J. Med Hypotheses (2001); 56(3):367-371.

2. Javaid MK, Crozier SR, Harvey NC, et al. Lancet (2008); 367(9504): 36-43.

3. ORiordan MN, Kiely M, Higgins JR, et al. Irish Med J (2008); 101(8): 1-3.

4. Holmes VA, Barnes MS, Alexander HD, et al. BJN (2009); 102, 876-888. 